\title{
The Fukushima nuclear disaster is ongoing
}

\author{
Andrew R. Marks \\ Department of Physiology and Cellular Biophysics, Clyde and Helen Wu Center for Molecular Cardiology, College of Physicians and Surgeons, Columbia University Medical Center, New York, New York, USA.
}

\begin{abstract}
The 5th anniversary of the Fukushima disaster and the 30th anniversary of the Chernobyl disaster, the two most catastrophic nuclear accidents in history, both occurred recently. Images of Chernobyl are replete with the international sign of radioactive contamination (a circle with three broad spokes radiating outward in a yellow sign). In contrast, ongoing decontamination efforts at Fukushima lack international warnings about radioactivity. Decontamination workers at Fukushima appear to be poorly protected against radiation. It is almost as if the effort is to make the Fukushima problem disappear. A more useful response would be to openly acknowledge the monumental problems inherent in managing a nuclear plant disaster. Lessons from Chernobyl are the best predictors of what the Fukushima region of Japan is coping with in terms of health and environmental problems following a nuclear catastrophe.
\end{abstract}

Five years after a tsunami caused the Fukushima nuclear accident in Japan, cleanup of radioactive contamination is ongoing and a formerly vibrant farming region lays largely fallow. A recent visit to northeast Japan revealed wholly unexpected aspects of the impact of the meltdown of three nuclear reactors. The area devastated by the nuclear accident is easily accessed by a two-hour train ride from Tokyo to the city of Fukushima. It is then possible to rent a car and drive to within $18 \mathrm{kM}$ of the reactors, which are still in meltdown.

On the train, digital banners in Japanese and English encourage passengers to visit the beautiful cherry trees in the Fukushima district. In the rental car agency, glossy pamphlets exclaim the beauty of the region and feature the brilliant pink blossoms. On a recent April afternoon, the cherry blossoms were indeed spectacular. The roads deep into the region affected by the radioactive plume that engulfed the area in March of 2011 are clearly marked and readily accessible in a car rented at the Fukushima rail station. My Japanese-speaking colleague translated the rental agency's map as indi- cating an "area not to return to," which we carefully avoided.

Following route 114 traveling east toward the coast, progressively larger piles of large black plastic bags filled with dirt appeared on the roadside. At first, there were piles of several hundred such bags, each approximately five feet wide by five feet in height, methodically stacked one upon the other. Of note, similar bags appear to be used elsewhere in Japan to hold debris at construction and yard cleaning sites. Each bag was numbered with a white marker.

Approaching the eastern coast of Japan, the piles of bags on the roadside were more frequent and larger and larger and larger. As route 114 progresses toward the exclusion zone indicated on the car rental agency's map, the piles of plastic bags filled with dirt reach unimaginable dimensions. Numbered in the many thousands, they eventually fill entire valleys that recede off into the horizon. In some instances, the piles of black plastic bags are covered with blue tarps with pipes inserted into their tops, presumably to provide ventilation.

Roadside radiation monitoring stations are placed near now abandoned homes, many of which are still decorated with plantings of flowers and the blossoming cherry trees that are found in the yards of most homes in this region. The readings on the radiation monitors ranged from 0.2115 to 1.115 microsieverts per hour, a measure of the relative risks imparted to biological tissues by ionizing radiation. One microsievert per hour is equivalent to four airport security screenings per hour and is almost twice the annual limit for occupational whole-body radiation dose limits established by the nuclear regulatory commission. One sievert total exposure causes a $5.5 \%$ risk of cancer (1).

To understand the health risks associated with ongoing radiation contamination and cleanup in the Fukushima region, the best comparator is Chernobyl. Two of the most important public health issues related to both the Chernobyl and the Fukushima disasters are thyroid cancers and posttraumatic stress disorder (PTSD). Assessing the effects of these nuclear accidents on the risk of thyroid cancer is confounded by the fact that the mere collection of data required to make the diagnosis (e.g., thyroid scans and ultrasounds) necessitates extranormal surveillance. Thus, true control populations are not available. Nevertheless, there have been reports of increased rates of thyroid cancer following the Chernobyl nuclear accident (2), and extrapolation from that incident to Fukushima is reasonable but as-yet unproven. The incidence of PTSD is understandably quite high following nuclear accidents (3). There are no controlled experimental data available to assess the ongoing risks of chronic lowlevel radiation now present throughout the Fukushima region. Thus, it is imperative that epidemiological data are collected as thoroughly as possible to provide insight concerning the risks of long-term lowlevel environmental radiation. Similarly, it is imperative that data are collected concerning the spread of radioactivity from the nuclear plant disaster via water (e.g., streams running through the region should 


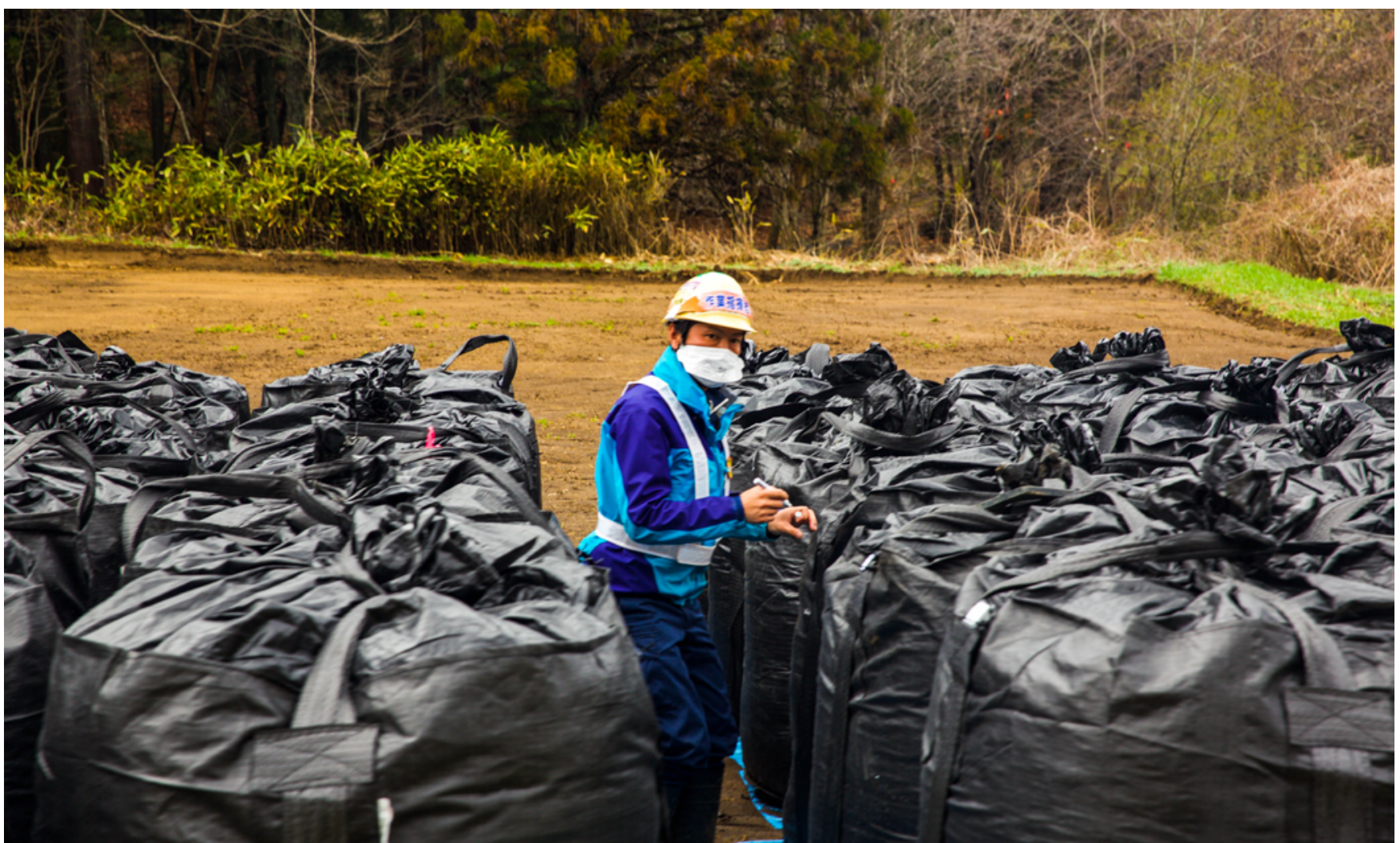

Figure 1. Worker at radioactivity decontamination site near Fukushima labeling bags filled with topsoil removed from contaminated areas. Image credit: Andrew R. Marks.

be sampled regularly) and via animals (in particular birds should be banded and monitored to determine how they may be vectors for spreading radioactivity in seeds and other forms throughout Japan).

Just outside the town of Iitate, brilliant pink flags, which are the same color used for the advertisements designed to attract tourists to view the cherry blossoms in the region, flap in the breeze, announcing (only in Japanese) "radioactivity removal." At one particularly large site near the town of Iitate, a constant stream of large trucks with entirely open containers was streaming into an excavation site located at a large mountain of brown dirt. Huge shovels were digging dirt and placing it onto conveyer belts pouring the dirt into the open trucks, which were leaving the site heading south. The men and women handling this contaminated dirt were wearing outfits similar to construction workers observed in other regions of Japan, including helmets, masks, gloves, and overalls (Figure 1). Over an approximately 5 -hour period of driving through the region, the only police observed were at the turn around marking the edge of the restricted zone. No military presence was observed. On several occasions, workers were seen handling the plastic bags of radioactively contaminated dirt without gloves.

During the entire afternoon of driving through the region not a single sign warning of the potential dangers of radioactive contamination was observed in any language other than Japanese. There was no security at most of the contaminated sites, and thousands of plastic bags of contaminated dirt were piled high in areas without any supervision or even a fence to prevent access from the public roadway. Birds flew all through the area, presumably transporting radioactive seeds and leaving contaminated droppings throughout Japan.

It is estimated that over 100,000 individuals have been displaced from their homes due to the reactor meltdown (4). Some have been relocated to far away cities, including Tokyo. During my visit, a group of five elderly women arrived on the same train as we did and were escorted onto a waiting bus to be driven to see the cherry blossoms decorating the village they used to live in. Other displaced former residents of now unlivable villages are perhaps less fortunate and have been relocated to one of the numerous "temporary" dwellings dotting the region indicated by convenient roadside signs. Many of these were immediately adjacent to radioactivity detectors indicating levels of at least 1 microsievert per hour.

Ironically, during myvisit to Fukushima on April 14, 2016, an earthquake rocked the Kumamoto region of Japan, ultimately causing at least 42 deaths and displacing thousands. This region contains the only working nuclear reactor remaining in Japan. Too far away to be felt in Fukushima, it was nevertheless a harsh reminder of the continued risk for further damage to the reactors already in meltdown.

The continued high level of radioactivity removal efforts in the Fukushima region (entire hill sides have been denuded of surface soil) indicate that the Japanese government knows the health threat caused by the contamination remains. The lack of security, the failure to provide any of the internationally accepted 
protective warnings against radioactivity contamination (e.g., the universal threearmed black and yellow sign warning of radioactivity), and the absence of any warning signs for non-Japanese-speaking individuals, despite the active advertising campaign to attract tourists to view the cherry blossoms on this beautiful region of Japan, is disturbing. The possibility that individuals could access enormous amounts of radioactively contaminated dirt and transport it to a sensitive area in Japan or elsewhere is frightening.

\section{About the author}

Andrew R. Marks is the chair of the Department of Physiology, founding director of the Clyde and Helen Wu Center for Molecular Cardiology, and professor of Medicine and Physiology and Cellular Biophysics at Columbia University. He is a member of the National Academy of Sciences, the National Academy of Medicine, and the American Academy of Arts and Sciences and served as editor in chief of the JCI from 2002 to 2007. His research focuses on the regulation of ryanodine receptor calcium release channels that control excitation-contraction coupling in cardiac and skeletal muscle.

Address correspondence to: Andrew R. Marks, Department of Physiology and Cellular Biophysics, Clyde and Helen Wu Center for Molecular Cardiology, College of Physicians and Surgeons, Columbia University Medical Center, 1150 St. Nicholas Avenue, Russ Berrie Medical Science
Pavilion, Room 520, New York, New York 10032, USA. Phone: 212.851.5340; E-mail: arm42@columbia.edu.

1. [No authors listed]. The 2007 Recommendations of the International Commission on Radiological Protection. ICRP publication 103. Ann ICRP. 2007;37(2-4):1-332.

2. Tuttle RM, Vaisman F, Tronko MD. Clinical presentation and clinical outcomes in Chernobyl-related paediatric thyroid cancers: what do we know now? What can we expect in the future? Clin Oncol (R Coll Radiol). 2011;23(4):268-275.

3. Ben-Ezra M, et al. From Hiroshima to Fukushima: PTSD symptoms and radiation stigma across regions in Japan. J Psychiatr Res. 2015;60:185-186.

4. Yamashita S, Radiation Medical Science Center for the Fukushima Health Management Survey. Comprehensive health risk management after the Fukushima nuclear power plant accident. Clin Oncol (R Coll Radiol). 2016;28(4):255-262. 